\title{
Latest journal news and introduction to the September issue of environment systems and decisions
}

\author{
Zachary A. Collier ${ }^{1} \cdot$ James H. Lambert $^{1} \cdot$ Igor Linkov $^{2}$
}

Published online: 2 August 2016

(c) Springer Science+Business Media New York 2016

The Editorial Board of Environment Systems \& Decisions is proud and excited to introduce the current published issue, featuring papers that are international in origin, broad in application domain, and diverse in methodological approach.

The issue begins with a perspectives article from Angeler et al. (2016) which discusses the current applications and future opportunities for panarchy theory within the environmental sciences. The first research article by Kojima et al. (2016) details a model which estimates particulate matter and $\mathrm{CO}_{2}$ emissions generated from passenger vehicles under a number of emission standards and policies. Norén et al. (2016) compare the flood risk assessment tools and risk management practices between producers of drinking water. In an example of health risk assessment, Islam et al. (2016) calculated the health risks of multiple heavy metals in commonly consumed fish and used principal component analysis to determine anthropogenic sources of these metals. Yatsalo et al. (2016) demonstrate case studies of a decision support system that integrates GIS and multiple criteria decision-making techniques. Al-Zu'bi (2016) provides a detailed account of gaps in Jordan's climate change risk governance framework and provides a roadmap for improvement. From the

Igor Linkov

Igor.Linkov@usace.army.mil

Zachary A. Collier

Zac4nf@virginia.edu

James H. Lambert

Lambert@virginia.edu

University of Virginia, Charlottesville, VA, USA

2 US Army Engineer Research \& Development Center, Concord, MA, USA perspective of conservation biology, Colyvan (2016) provides a review of value of information techniques which can aid practitioners faced with the high costs of data acquisition. Lastly, González Afanador et al. (2016) use spatial analysis to investigate the relationships between property size, landscape structure, and habitat fragmentation and the implications of the findings on habitat management.

Google Scholar (www.scholar.google.com) recently published their journal metrics for 2016, which covers the citations to journals for the previous five complete years. Environment Systems \& Decisions earned an h5-index of 14 and an h5median of 19. According to Google, the h5-index is defined as: "the largest number $\mathrm{h}$ such that $\mathrm{h}$ articles published in 2011-2015 have at least $\mathrm{h}$ citations each" and the h5-median is the "median number of citations for the articles that make up its h5-index." This is an encouraging development and signifies that the research published in Environment Systems \& Decisions is having a far-reaching impact.

Finally, future special issues are currently being planned. Environment Systems \& Decisions is still accepting submissions for our special issue focusing on research published by students and early-career professionals. Another special issue will be published featuring invited papers from the recent International Symposium on Sustainable Systems and Technology (ISSST, http://issst2016.net). Finally, a special issue entitled "Disruptions, Adaptation, and Resilience in Socio-Technical Systems: Analysis, Data, and Validation" is currently accepting submissions.

\section{References}

Al-Zu'bi M (2016) Jordan's climate change governance framework: from silos to an intersectoral approach. Environ Syst Decis. doi:10.1007/s10669-016-9602-9 
Angeler DG, Allen CR, Garmestani AS, Gunderson LH, Linkov I (2016) Panarchy use in environmental science for risk and resilience planning. Environ Syst Decis. doi:10.1007/s10669016-9605-6

Colyvan M (2016) Value of information and monitoring in conservation biology. Environ Syst Decis. doi:10.1007/s10669-0169603-8

González Afanador E, Kjelland ME, Wu X, Wilkins N, Grant WE (2016) Ownership property size, landscape structure, and spatial relationships in the Edwards Plateau of Texas (USA): landscape scale habitat management implications. Environ Syst Decis. doi:10.1007/s10669-016-9604-7

Islam MS, Ahmed MK, Habibullah-Al-Mamun M, Raknuzzaman M, Ali MM, Eaton DW (2016) Health risk assessment due to heavy metal exposure from commonly consumed fish and vegetables. Environ Syst Decis. doi:10.1007/s10669-016-9592-7

Kojima N, Tokai A, Nakakubo T, Nagata Y (2016) Policy evaluation of vehicle exhaust standards in Japan from 1995 to 2005 based on two human health risk indices for air pollution and global warming. Environ Syst Decis. doi:10.1007/s10669-015-9582-1

Norén V, Hedelin B, Bishop K (2016) Drinking water risk assessment in practice: the case of Swedish drinking water producers at risk from floods. Environ Syst Decis. doi:10.1007/s10669-016-95883

Yatsalo B, Gritsyuk S, Sullivan T, Trump B, Linkov I (2016) Multicriteria risk management with the use of DecernsMCDA: methods and case studies. Environ Syst Decis. doi:10.1007/ s10669-016-9598-1 